\title{
Metforminin Melanom Cilt Kanseri Hücreleri Üzerindeki Etkisinin Araştırılması
}

\section{Investigating of Effects of Metformin on Melanoma Skin Cancer}

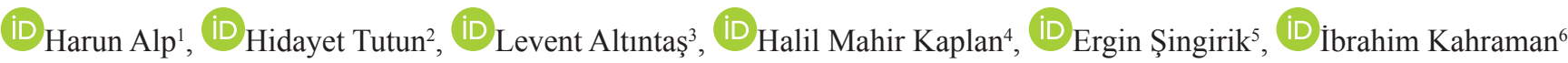

${ }^{1}$ Karamanoğlu Mehmetbey University, Medicine Faculty, Medical Pharmacology Department, Karaman.

${ }^{2}$ Burdur Mehmet Akif Ersoy University, Veterinary Faculty, Pharmacology and Toxicology Department, Burdur.

${ }^{3}$ Ankara University, Veterinary Faculty, Pharmacology and Toxicology Department, Ankara

${ }^{4}$ Cukurova University, Medicine Faculty, Pharmacology Department, Adana.

${ }^{5}$ Cukurova University, Medicine Faculty, Medical Pharmacology Department, Adana.

${ }^{6}$ Hatay Mustafa Kemal University, Tayfur Ata Sokmen Faculty, Biophysics Department, Hatay.

\section{$\ddot{\mathrm{Oz}}$}

Amaç: Kanserlerde kemoterapötiklere gösterilen dirençte ve kanser gelişiminde apoptozisin önemli rolü vardır. Metformin tip 2 diyabet tedavisinde kullanılan güvenli, ucuz ve etkili bir ilaçtır. Ayrıca, antikanser etkilerinin olduğuna dair kanıtlar olmasına rağmen metforminin bu etkiyi hangi mekanizmalar ile gerçekleştirdiği açık değildir. Bu nedenle, bu çalıșmada metformin cilt kanseri hücrelerinde Bcl-2, caspaz-3, bax, wee-1, AIF, grp78 ve gadd153 düzeyleri üzerine etkileri araştırıldı.

Gereç ve Yöntem: Deri kanseri hücrelerine (B16F10) metformin uygulandı ve kaspaz-3, bcl-2, hafta 1, gadd153, grp78 ve AIF seviyeleri ELISA kullanılarak ölçüldü.

Bulgular: Çalışmamızda metforminin cilt kanseri hücrelerinde apoptozis proteinlerini (caspaz-3, wee 1, gadd153, grp78 ve AIF) arttırdığı ve antiapoptotik markırı (bcl-2) azalttı̆̆ belirlendi.

Sonuç: Çalışma sonuçları metforminin melanom cilt kanseri üzerine apoptotik etkisinin olduğunu gösterdi.

Anahtar Kelimeler: Metformin, melanom cilt kanseri, kaspaz-3, bcl-2, wee 1, gadd153, grp78, AIF.

\begin{abstract}
Aim: Apoptotic pathways are important for resistance to chemotherapeutics drugs and cancer development. Metformin is a safe, inexpensive and effective drug used to treat type 2 diabetes. Furthermore, although there is evidence of anticancer effects, the mechanisms by which metformin exerts the effects are unclear.
\end{abstract} Therefore, it was aimed to investigate Bcl-2, kaspaz-3, bax, wee-1, AIF, grp78 and gadd153 levels in metformin treated skin cancer cells.

Materials and Methods: The skin cancer cells (B16F10) were treated with metformin and kaspase-3, bcl-2, wee 1, gadd153, grp78 and AIF levels were analyzed by using ELISA.

Result: Treatment of metformin increased of proapoptotic proteins (kaspase-3, bcl-2, wee 1, gadd153, grp78 and AIF) and decreased antiapoptotic protein (bcl2).

Conclusion: In conclusion, this study showed that metformin has apoptotic effect on melanoma skin cancer.

Keywords: Metformin, melanoma skin cancer, kaspase-3, bcl-2, wee 1, gadd153, grp78, AIF.

Yazışma Adresi: Levent Altıntaş, Ankara University, Veterinary Faculty, Pharmacology and Toxicology Department, 06110, Diskap1, Ankara.

E-Posta: leventaltintas@hotmail.com

Alınma Tarihi : 20.09.2019 / Kabul Tarihi : 06.07.2020 / Yayımlanma Tarihi : 15/06/2021 
Metformin, Galega officinalis isimli bitkiden elde edilen ve tip 2 diyabetin tedavisinde kullanılan etkili ve güvenli bir ilaçtır (1). Metformin karaciğerdeki glukoneogenezi azaltır ve periferik dokular tarafından glikoz alımını teşvik eder, böylece kan glukozu ve insülin seviyelerini düşürür (2). Metforminin bu etkisini genellikle sitoplazma içinde bulunan hücresel enerji sensörü olarak görev yapan adenozin monofosfat kinaz (AMPK) yolağını tetikleyerek gösterdiği belirtilmektedir (3). Ayrıca, metforminin antikanser etkileri olduğuna dair kanıtlar da vardır (4). Yapılan araştırmalar metformin ile tedavi edilen diyabetik hastalarda kanser insidansı ve mortalite riskinin daha az olduğunu göstermiştir. Metforminin antikanser etkilerinin hangi mekanizmalar aracılığıyla oluştuğu halen kesin olarak belirlenemese de bu etkilerini doğrudan veya dolaylı birçok mekanizma ile gösterdiği düşünülmektedir (5-7). $\mathrm{Bu}$ mekanizmalardan biri AMPK aktivasyonu ile fosfatidilinositol 3-kinaz (PI3K)/AKT/ rapamisin protein kompleksinin memeli hedefi (mTOR) yolağının baskılanmasıdır. $\mathrm{Bu}$ yolak hücre büyümesini ve metabolizmayı düzenleyen korunmuş bir sinyal yolağıdır. mTOR, S6 kinaz (S6K) ve translasyon başlatma faktörünün 4E bağlanma protein 1 (4EBP1) gibi protein sentezinde yer alan iki önemli hedefi doğrudan aktive eder (8). mTORC1 (rapamisin kompleksi 1'in memeli hedefi) mTOR'un iki fonksiyonel kompleksinden biridir ve AMPK ile negatif yönde regüle edilir. AMPK, mTORC1 yolağını doğrudan inhibe; mTOR yolağını inhibe eden tuberoz skleroz kompleks protein 2'yi (TSC2) ise dolaylı yoldan fosforile ederek; protein sentezinin ve hücre büyümesinin yavaşlamasına yol açar (9). Metforminin AMPK modülasyonu yoluyla mTOR aktivitesini inhibe ederek, çeşitli kanser türlerinin progresyonunda olumlu etkiler sağladığını bildiren çalışmalar vardır (10-12). Bunun yanında metforminin mTORC1'i AMPK ve TSC2 yolağından bağımsız RAG GTPaz aracılığıyla inhibe ettiği de bildirilmiştir (13)

Metforminin antikanser etkisini insülin benzeri büyüme faktörü (IGF), insülin ve insan epidermal büyüme faktörü reseptörü 2 (HER2) aracılı sinyalleri azaltarak ve mTOR sinyal inhibisyonu yolağıyla anjiyogenez inhibisyonu ve apoptoz indüksiyonu ile gösterdiği ileri sürülmektedir $(2,14)$. Karaciğer kinaz B1 (LKB1) olarak adlandırılan bir protein, tümör baskılayıcı genin ürünüdür. AMPK katalitik alt ünitesinin fosforilasyonu, LKB1 varlığında gerçekleşir ve adenozin monofosfat (AMP) tarafindan kolaylaştııılır $(15,16)$. AMPK aktivasyonu, mTOR sinyalinin inhibisyonuna yol açar, bu nedenle karaciğer tarafindan glukoneogenez azaltılır. Metformin, hücresel düzeyde hem dolaylı (insüline bağımlı) hem de doğrudan (insülinden bağımsız) etkiler oluşturur. Doğrudan etkisine AMPK aktivasyonu ve karaciğerde glukoneogenezin inhibe edilmesine, kanser sentezinde protein sentezi ve hücre proliferasyonuna yol açan mTOR sinyal yolunun azaltılması aracılık eder $(10,17,18)$. Metformin ayrica insan meme kanseri hücrelerinde, mTOR yolağını inhibe ederek, HER-2 protein ekspresyonunu azaltır. Bu etkinin mTOR efektörü p70S6K1'in inhibisyonu ile meydana geldiği düşünülmektedir (19). Kanseri baskılama özelliği olan p53'ün AMPK ile ekspresyonu ve fosforilasyonunun, metforminin antikanser etki mekanizmasındaki rolü halen tartışma konusudur (20).

Metforminin antikanser etkilerinin hangi mekanizmalar aracılığıyla oluştuğu halen kesin olarak belirlenemese de bu etkilerini doğrudan veya dolaylı birçok mekanizma ile gösterdiği aşikardır $(21,22)$. Bu çalışmada, metforminin melanom cilt kanseri hücrelerinde kaspaz-3, bcl-2, bax, wee 1, gadd153, grp78 ve AIF protein düzeyleri ve aktiviteleri üzerine etkileri araştırılmıştır.

\section{Hücre Kültürü}

Fare deri melanoma hücreleri (ATCC, B16F10), L-glutamin (\%1) (Hyclone), penisilin $(100 \mu \mathrm{g} / \mathrm{ml})$, streptomisin $(100 \mathrm{U} / \mathrm{ml})$ ve \%10 Fetal Bovine Serum (FBS) (Hyclone) eklenmiş Dulbecco's modification of Eagle's medium (DMEM) (Gibco) içerisinde üretildi. Hücreler, $75 \mathrm{~m}^{2}$ hücre kültürü flasklarında her flaska $2 \times 10^{6}$ hücre olacak şekilde tek tabaka halinde yetiştirildi. $37^{\circ} \mathrm{C}$ sicaklıkta ve $\% 5$ 'lik CO ${ }^{2}$ li etüvde inkübe edildi. Metformin (Sigma) $10 \mathrm{mM} / \mathrm{L}$ miktarında hücre mediumu içerisinde çözdürüldü (23). Çalışmada metformin uygulanan 6 flask ve metformin uygulanmayan (kontrol grubu) 6 flask toplamda 12 flask hücre kullanıldı. Bu hücreler 48 saat metformin ile muamele edilip ELISA yöntemiyle protein analizleri yapılması için homojenize edildi.

\section{MTT Testi}

MTT (3-(4,5-Dimethylthiazol-2-yl)-2,5-Diphenyltetrazolium Bromide) testi mitokondriyal aktiviteyi ölçmek için kullanıldı (24). Hücreler 96 kuyucuklu plakalara $\left(3 \times 10^{3}\right.$ hücre $\left./ \mathrm{ml}\right)$ ekildi. 48 saatlik farklı konsantrasyonlardaki metmorfin maruziyetinin ( $5 \mathrm{mM}, 10 \mathrm{mM}$ ve $20 \mathrm{mM}$ miktarlarında) ardından hücre kültür mediumu atıldı ve hücreler $100 \mu \mathrm{l}$ MTT çözeltisi ile $(0,5 \mathrm{mg} / \mathrm{ml}$ miktarında DMEM içinde çözdürüldü) 2 saat $37^{\circ} \mathrm{C}$ 'de ve $\% 5 \mathrm{CO}_{2}$ 'de inkübe edildi. MTT çözeltisi daha sonra atıldı ve her bir kuyucuğa $100 \mu$ l Dimetil sülfoksit eklendi. Optik yoğunluk (OD), $550 \mathrm{~nm}$ 'de bir mikroplaka okuyucuda (EL800, Bio-Tek Instruments, Inc.) okundu. Canlılık, her bir durum için elde edilen OD ortalamasının, kontrol (metformin içermeyen) koşuluna oranı olarak hesaplandı.

\section{Hücre Homojenizasyonu}

Her flasktan mediumlar uzaklaştırıldıktan sonra $5 \mathrm{ml}$ PBS ile yıkandı. Ardından $3 \mathrm{ml}$ Tripsin-EDTA eklendikten sonra 3 dakika beklendi ve üzerine $4 \mathrm{ml}$ medium eklendikten sonra hücreler kaldırılarak 15 ml tüplere (Falkon) alındı. Tüpler $+4^{\circ} \mathrm{C}$ sıcaklıkta 2000 RPM'de 10 dakika santrifüj yapıldıktan sonra sıvı kısımları atıldı. Yıkamak için üzerine tüplere $5 \mathrm{ml}$ PBS eklendi ve $+4^{\circ} \mathrm{C}$ sicaklıkta 2000 RPM'de 10 dakika santrifüj yapıldıktan sonra PBS uzaklaştırıldı. Tüplerdeki hücreler üzerine $250 \mu 1$ RIPA buffer (Radio-Immunoprecipitation Assay), 2,5 $\mu$ 1 PMSF (Phenylmethylsulfonyl fluoride, 200mM), 2,5 $\mu 1$ sodyum vanadat $(100 \mathrm{mM}), 2,5 \mu$ l proteaz inhibütörü eklendi ve sonra hücreler buz üzerinde ultrasonik homojenizatör cihazı yardımıyla parçalanarak homojenatlar elde edildi. Homojenatlar 10000 RPM'de 10 dakika santrifüj edilip üstte ayrılan kısımlar (süpernatantlar) alınıp, alttaki çökeltiler (pelletler) atıldı.

\section{Protein Miktar Tayini}

Homojenize edilmiş hücrelerin protein miktar tayini Bradford yöntemi ile yapıldı. Sı ̆̆ır serum albümini $(1 \mu \mathrm{g} / \mathrm{ml})$ kullanılarak 1,2 , $3,5,7,8,10(\mu \mathrm{g} / \mathrm{ml})$ konsantrasyonlarda standart hazırlanıp her bir örnekten $10 \mu \mathrm{l}$ alınarak distile su ile $100 \mu$ l'ye tamamlandı. Standart ve örneklerin üzerine $1 \mathrm{ml}$ Bradford solüsyonu eklenip vorteksle karıştırıldıktan sonra spektrofotometrede (Rayto Life Reader, China) 595 nanometre dalga boyunda absorbans miktarları ölçüldü. Prism programında (GraphPad Software, USA) çizilen standart eğriye göre protein miktar tayini $\mu \mathrm{g} / \mu 1$ cinsinden yapıldı. Protein miktar tayini ELISA deneylerinin standardizasyonu için yapılmıştır.

Metforminin Melanom Cilt Kanserine Etkisi - Alp ve ark. 


\section{ELISA Testi}

Bcl-2, kaspaz-3, bax, wee-1, AIF, grp78 ve gadd153 düzeyleri Shenzhen Genesis Teknology (Guangdong, China) firmasından satın alınan ELISA kitleri ile üreticinin protokollerine göre tespit edildi.

\section{İstatistik}

Protein miktarlarının gruplar arasında istatistiksel önemini belirlemek için Student's t-testi kullanıldı. İstatistiksel analizler SPSS yazılım paketi ile yapıldı. Tüm değerler ortalama \pm SE olarak ifade edildi. Gruplar arasındaki farkların $\mathrm{p}<0,05$ seviyesinde istatistiksel yönden anlamlı olduğu kabul edildi.

\section{Bulgular}

$\mathrm{Bu}$ çalışmada, metformin cilt kanseri hücrelerinde antiapoptotik protein olan bcl-2'nin düzeyini (Şekil 1) anlamlı olarak azaltırken, kaspaz-3 (Şekil 1), bax (Şekil 1), wee-1 (Tablo 1), AIF (Tablo 1), gadd153 (Tablo 1) ve grp78 (Tablo 1) proteinlerini anlamlı olarak arttırdı. Ayrıca, metformin cilt kanseri hücrelerinin proliferasyonunu doza bağlı bir şekilde önemli ölçüde inhibe ettiği gözlendi (Şekil 1).

Tablo 1. Metforminin wee 1, AIF, gadd153 ve grp78 proteinlerinin ekspresyonları üzerine etkileri.

\begin{tabular}{lll}
\hline Proteinler & Kontrol & Metformin \\
\hline wee 1 & $0,52 \pm 0,02 \mathrm{pg} / \mathrm{ml}$ & $0,95 \pm 0,012 \mathrm{pg} / \mathrm{ml}^{*}$ \\
AIF & $0,45 \pm 0.01 \mathrm{pg} / \mathrm{ml}$ & $1,82 \pm 0,011 \mathrm{pg} / \mathrm{ml}^{*}$ \\
& & \\
gadd153 & $0,29 \pm 0,019 \mathrm{pg} / \mathrm{ml}$ & $1,53 \pm 0,08 \mathrm{pg} / \mathrm{ml}{ }^{*}$ \\
grp78 & $0,75 \pm 0,02 \mathrm{pg} / \mathrm{ml}$ & $2,23 \pm 0,06 \mathrm{pg} / \mathrm{ml}^{*}$ \\
\hline
\end{tabular}

Sonuçlar ortalama \pm SE olarak sunulmuştur. ${ }^{*}$ İstatistiksel analiz: Student $\mathrm{t}$ test. $(*$ : Kontrole göre $\mathrm{P}<0,05$.).

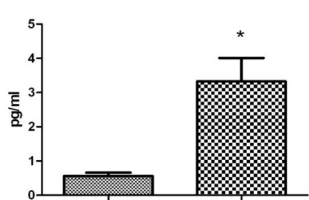

bax

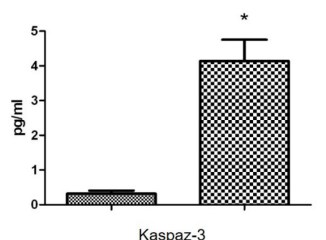

Kaspaz-3
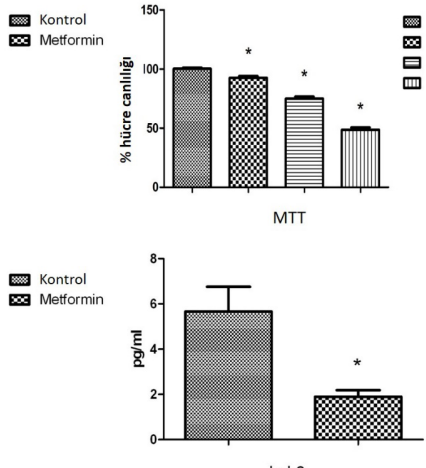

$\mathrm{bcl}-2$
Şekil 1. Metforminin melanom cilt kanserindeki bcl-2 (n=6), Kaspaz-3 (n=6) ve Bax $(n=6)$ proteinlerinin ekspresyonlarına etkisi ve MTT sonuçları. Sonuçlar ortalama $\pm \mathrm{SE}$ olarak sunulmuştur.

İstatistiksel analiz: Student $t$ test. (* : Kontrole göre $\mathrm{P}<0,05)$.

\section{Tartışma}

Metformin, çoklu etki bölgeleri ve çoklu moleküler mekanizmaları olan karmaşık bir ilaçtır. Fizyolojik olarak, metformin, glukoz üretimini düşürmek için doğrudan veya dolaylı olarak karaciğere etki eder ve glukoz kullanımını artırmak, glukagon benzeri peptid-1 (GLP- 1)'i arttırmak ve mikrobiyomu değiştirmek için bağırsakta etki eder $(25,26)$. Moleküler seviyede, metformin karaciğerdeki mitokondriyal solunum zincirini inhibe eder, AMPK'nin aktivasyonuna yol açar, insülin duyarlılı̆̆ını arttırır (yağ metabolizması üzerindeki etkiler yoluyla) ve siklik adenozin monofosfot (sAMP)'yi düşürür, böylece glukoneojenik enzimlerin ekspresyonunu azaltır. Metformin ayrıca, fruktoz-1,6-bisfosfatazın AMP tarafindan inhibisyonunu içeren karaciğer üzerinde AMPK' dan bağımsız etkilere de sahiptir $(27,28)$.

Birçok çalışma, metformin ile tedavi edilmiş diyabetik hastalarda kanser riskinin azaldığını göstermiştir $(2,29,30)$. Yapılan kapsamlı bir meta-analiz çalışmasında, metforminin pankreas kanseri, hepatoselüler karsinoma ve kolon kanserinde kanser insidansını \%3050 azalttığı tespit edilmiştir(31). Bu çalışmalar metformin kullanımının kansere karşı koruyucu etkisinin olabileceğini düşündürmektedir. Özellikle meme kanserinde apoptotik etkilerini gösteren ve tedavide kullanılmasını destekleyen yayınlar bulunmaktadır (32,33). Metforminin prostat kanseri, akciğer kanseri, yumurtalık kanseri, endometriyal kanser ve pankreas kanseri üzerindeki etkileri ile ilgili de yapılmış birçok çalışma mevcuttur (34-40).

Kanserlerde kemoterapötiklere gösterilen dirençte ve kanser gelişiminde apoptozisin önemli rolü vardır. Metformin güvenli, ucuz, şeker hastalarında sıkça kullanılan ve etkili ilaçlar arasında olduğu düşünülürse cilt kanseri üzerine yararlı etkileri büyük önem arz etmektedir. $\mathrm{Bu}$ çalışmada, metformin cilt kanseri hücrelerinin proliferasyonunu doza bağlı bir şekilde önemli ölçüde inhibe ettiği gözlendi. Metformin A498 hücrelerinde (41), ovaryum kanser hücrelerinde $(23,42)$ ve meme kanseri hücrelerinde (MCF-7) (43) doza bağımlı olarak proliferasyonu inhibe ettiği gözlenmiştir. Bu çalışmanın sonuçları yapılan bu çalışmaların sonuçları ile uyumlu bulunmuştur.

$\mathrm{Bu}$ çalışmada, metformin cilt kanseri hücrelerinde antiapoptotik protein olan bcl-2'nin düzeyini anlamlı olarak azaltırken, kaspaz-3, bax, wee-1, AIF, gadd153 ve grp78 proteinlerini anlamlı olarak arttırd1. Hücre dış1 faktörlerle düzenlenen $\mathrm{Bcl}-2$ veya Bax gibi birçok ölüm ve hayatta kalma genleri apoptozda rol oynar (44). Proapoptotik Bcl-2 familyas1 üyelerinin (bax, bad) anti-apoptotik bcl2 familyası (bcl-2, Bcl-XL ve Mcl-1) üyelerine oranı arttıkça, dış mitokondri zarında gözenekler oluşur, apoptojenik kaspazları aktive etmek ve apoptozu indüklemek için mitokondriyal proteinler serbest bırakılır (45). Metformin ile muamele edilmiş epitelyal ovaryum kanseri hücrelerinde kaspaz 3/7 aktivasyonunda artma, fosfo-Bcl-2, Bcl-2, Bcl-xL ve Mcl-1 anti-apoptotik proteinlerin ekspresyonunda bir azalma ve proopoptotik proteinlerin Bax ve fosfo-Bad'ın ekspresyonunda bir artma gözlenmiştir (23). Başka bir çalışmada benzer şekilde metformin primer ovaryum kanseri hücrelerinde apoptozis, Bcl-2 ekspresyonunu azaltarak ve Bax ekspresyonunu arttırarak tetiklediği gözlenmiştir (42). Ayrıca, metformin ile uzun süreli verilmesi melanoma tedavisinde kaspaz 3 ile apoptozu indüklediğini gözlenmiştir (46). Meme kanseri hücrelerinde (MCF7) benzer şekilde kaspaz-3, Bax protein ekspresyonunu arttırırken, Bcl-2 protein ekspesyonunu düşürmüştür (43). Bir protein kinaz olan Wee1 inhibisyonu, kanserde terapötik bir hedef olarak görülmektedir (47). Apoptoz indükleyici faktör (AIF), apoptoz indüksiyonu üzerine normal lokalizasyonundan mitokondriyal intermembran boşluğundan çekirdeğe yer değiştiren yeni bir memeli, kaspazdan bağımsız ölüm efektörüdür (48). Başka bir çalışmada araştırmacılar AIF'nin kaspazdan bağımsız hücre apoptozisindeki merkezi rolü nedeniyle, nükleer ve sitoplazmatik AIF seviyelerini western blot ile belirlenmiştir. Çalışma sonuçları, MDA-MB-231 hücrelerinin 
metformin ile işlemden sonra AIF'nin nükleer protein fraksiyonunda arttığını ve sitoplazmatik protein bölmesinde azaldığını göstermiştir. Araştırmacılar AIF'nin çekirdeğe translokasyon oranının arttığını ve daha sonra hücre ölüm oranının arttığını belirtmişlerdir (49).

Başka bir çalışmada insan kolorektal kanser (COLO 205) hücrelerinin silibinin ve metformin ile kombinasyon tedavisi sinerjistik olarak artmış PTEN ekspresyonu ve AMPK fosforilasyonu yoluyla hücre sağkalımının inhibe edilmesini sağladığ AIF ekspresyonunda bir artışa neden olduğu belirtilmiştir (50). Metforminin insan ovaryum kanser hücrelerinde grp78, gadd153 ve kaspaz 3 ekspresyonunu etkili bir şekilde arttırdığını bulunmuştur (51). Yapılan bir başka çalışmada metformin insan akciğer kanseri hücre hatlar1 A549 ve NCI-H1299'da apoptozise neden olduğunu ve hücrelerin çoğalmasını doza ve zamana bağlı bir şekilde önemli ölçüde inhibe ettiğini ve JNK / p38 MAPK yolağını ve GADD153'ü aktive ederek apoptozu indüklediğini bildirilmiştir (52). Yapılan bu çalışmada elde edilen sonuçlar ile farklı kanser hücre hatlarında metforminin etkilerinin araştırıldığ çalışmalarda elde edilen sonuçlar ile benzerdir.

\section{Sonuç}

Sonuç olarak çalışmamız metforminin melanom cilt kanseri hücre hattında hücre içi apoptotik yolakları aktive edip, antiapoptotik proteinleri inhibe ederek melanom cilt kanserinin üremesini azalttığını göstermiştir. Ayrıca bu çalışma metformin üzerine yapılacak bir sonraki aşama olan hayvan deneyi çalışmalarına da 1şık tutmaktadır.

\section{Teşekkür}

Bu çalışma Hatay Mustafa Kemal Üniversitesi Bilimsel Araştırma Projeleri Başkanlığı tarafından desteklenmiştir (Proje no. 16569).

\section{Kaynaklar}

1. Bailey CJ, Day C. Metformin: its botanical background. Practical Diabetes Int 2004; 21: 115

2. Del Barco S, Vazquez-Martin A, Cufi S, Oliveras-Ferraros C, Bosch-Barrera J, Joven J. et al. Metformin: multi-faceted protection against cancer. Oncotarget 2011; 2: 896-917.

3. Viollet B, Guigas B, Sanz Garcia N, Leclerc J, Foretz M, Andreelli F. Cellular and molecular mechanisms of metformin: an overview. Clin Sci 2012; 122 (6) 253-270.

4. Martin-Castillo B, Vazquez-Martin A, Oliveras-Ferraros C, Menendez JA. Metformin and cancer: doses, mechanisms and the dandelion and hormetic phenomena. Cell Cycle 2010; 9 (6): 1057-1064.

5. Evans JM, Donnelly LA, Emslie-Smith AM, Alessi DR, Morris AD. Metformin and reduced risk of cancer in diabetic patients. BMJ 2005; 330: 1304-1305.

6. Lee MS, Hsu CC, Wahlqvist ML, Tsai HN, Chang YH, Huang YC. Type 2 diabetes increases and metformin reduces total, colorectal, liver and pancreatic cancer incidences in Taiwanese: a representative population prospective cohort study of 800,000 individuals. BMC Cancer 2011; 11:20. doi: 10.1186/1471-2407-11-20.

7. Libby G, Donnelly LA, Donnan PT, Alessi DR, Morris AD, Evans JM. New users of metformin are at low risk of incident cancer: a cohort study among people with type 2 diabetes. Diabetes Care 2009; 32: 1620-1625.

8. Pulito C, Donzelli S, Muti P, Puzzo L, Strano S, Blandino G. microRNAs an cancer metabolism reprogramming: the paradigm of metformin. Ann Transl Med 2014; 2 (6): 58.

9. Hay N, Sonenberg N. Upstream and downstream of mTOR. Genes Dev 2004; 1816):926-945.

10. Dowling RJ, Zakikhani M, Fantus IG, Pollak M, Sonenberg N. Metformin inhibits mammalian target of rapamycin-dependent translation initiation in breast cancer cells. Cancer Research 2007; 67 (22): 10804-10812

11. Han G, Gong H, Wang Y, Guo S, Liu K. AMPK/mTOR-mediated inhibition of survivin partly contributes to metformin-induced apoptosis in human gastric cancer cell. Cancer Biol Ther 2015; 16 (1): 77-87

12. Honjo S, Ajani JA, Scott AW, Chen Q, Skinner HD, Stroehlein J. et al. Metformin sensitizes chemotherapy by targeting cancer stem cells and the mTOR pathway in esophageal cancer. Int J Oncol 2014; 45 (2): 567-574.

13. Kalender A, Selvaraj A, Kim SY, Gulati P, Brûlé S, Viollet B. et al. Metformin, independent of AMPK, inhibits mTORC1 in a rag GTPase-dependent manner. Cell

Genel Tip Derg 2021;31(2):111-115

114
Metab 2010; 11: 390-401

14. Jalving M, Gietema JA, Lefrandt JD, de Jong S, Reyners AK, Gans RO. et al. Metformin: taking away the candy for cancer? Eur J Cancer 2010; 46 (13): 23692380 .

15. Kahn BB, Alquier T, Carling D, Hardie DG. AMP-activated protein kinase: ancient energy gauge provides clues to modern understanding of metabolism. Cell Metabolism 2005; 1 (1): 15-25

16. Zhou G, Myers R, Li Y, Chen Y, Shen X, Fenyk-Melody J. et al. Role of AMPactivated protein kinase in mechanism of metformin action. The Journal of Clinical Investigation 2001; 108 (8): 1167-1174.

17. Alimova IN, Liu B, Fan Z, Edgerton SM, Dillon T, Lind SE. et al. Metformin inhibits breast cancer cell growth, colony formation and induces cell cycle arrest in vitro. Cell Cycle 2009; 8 (6): 909-915.

18. Zakikhani M, Dowling R, Fantus IG, Sonenberg N, Pollak M. Metformin is an AMP kinase-dependent growth inhibitor for breast cancer cells. Cancer Research 2006; 66 (21): 10269-10273.

19. Vazquez-Martin A, Oliveras-Ferraros C, Menendez JA. The antidiabetic drug metformin suppresses HER2 (erbB-2) oncoprotein overexpression via inhibition of the mTOR effector p70S6K1 in human breast carcinoma cells. Cell Cycle 2009; 8: 88-96.

20. Nelson LE, Valentine RJ, Cacicedo JM, Gauthier MS, Ido Y, Ruderman NB. A novel inverse relationship between metformin-triggered AMPKSIRT1 signaling and 553 protein abundance in high glucoseexposed HepG2 cells. Am J Physiol Cell Physiol 2012; 303: C4-C13. doi: 10.1152/ajpcell.00296.2011.

21. Cerezo M, Tichet M, Abbe P, Ohanna M, Lehraiki A, Rouaud F. et al. Metformin blocks melanoma invasion and metastasis development in AMPK/p53-dependent manner. Mol Cancer Ther 2013; 12: 1605-1615.

22. Li P, Zhao M, Parris AB, Feng X, Yang X. p53 is required for metformin-induced growth inhibition, senescence and apoptosis in breast cancer cells. Biochem Biophys Res Commun 2015; 464 (4): 1267-1274.

23. Yasmeen A, Beauchamp MC, Piura E, Segal E, Pollak M, Gotlieb WH. Induction of apoptosis by metformin in epithelial ovarian cancer: involvement of the Bcl-2 family proteins. Gynecologic Oncology 2011; 121 (3): 492-498.

24. Mossman T. Rapid colorimetric assay for cellular growth and survival: application to proliferation and cytotoxicity assays. J Immunol Methods 1983; 65 (1-2): 55-63.

25. Forslund K, Hildebrand F, Nielsen T, Falony G, Le Chatelier E, Sunagawa S. et al. Disentangling type 2 diabetes and metformin treatment signatures in the human gut microbiota. Nature 2015; 528: 262-266.

26. Preiss D, Dawed A, Welsh P, Heggie A, Jones AG, Dekker J. et al. Sustained influence of metformin therapy on circulating glucagon-like peptide-1 levels in individuals with and without type 2 diabetes. Diabetes Obes Metab 2017; 19: 356363.

27. Miller RA, Chu Q, Xie J, Foretz M, Viollet B, Birnbaum MJ. Biguanides suppress hepatic glucagon signalling by decreasing production of cyclic AMP. Nature 2013 ; 494: 256-260

28. Malek M, Aghili R, Emami Z, Khamseh ME. Risk of cancer in diabetes: the effect of metformin. ISRN Endocrinology, 2013.

29. Bowker SL, Majumdar SR, Veugelers P, Johnson JA. Increased cancer-related mortality for patients with type 2 diabetes who use sulfonylureas or insulin. Diabetes Care 2006; 29: 254-258

30. Landman GW, Kleefstra N, van Haterenm KJJ, Groenier KH, Gans ROB, Bilo HJG. Metformin associated with lower cancer mortality in type 2 diabetes: ZODIAC-16. Diabetes Care 2010; 33: 322-326.

31. Decensi A, Puntoni M, Goodwin P, Cazzaniga M, Gennari A, Bonanni B. et al. Metformin and cancer risk in diabetic patients: a systematic review and metaanalysis. Cancer Prev Res 2010; 3 (11): 1451-1461.

32. Cazzaniga M, Bonanni B, Guerrieri-Gonzaga A, Decensi A. Is it time to test metformin in breast cancer clinical trials? Cancer Epidemiol Biomarkers Prey 2009; 18: 701-705.

33. Goodwin PJ, Ligibel JA, Stambolic V. Metformin in breast cancer: time for action. J Clin Oncol 2009; 27: 3271-3273.

34. Bodmer M, Becker C, Meier C, Jick SS, Meier CR. Use of metformin and the risk of ovarian cancer: a case-control analysis. Gynecologic Oncology 2011; 123 (2): 200-204.

35. Buzzai M, Jones RG, Amaravadi RK, Lum JJ, DeBerardinis RJ, Zhao F. Systemic treatment with the antidiabetic drug metformin selectively impairs p53-deficient tumor cell growth. Cancer Res 2007; 67 (14): 6745-6752.

36. Cantrell LA, Zhou C, Mendivil A, Malloy KM, Gehrig PA, Bae-Jump VL. Metformin is a potent inhibitor of endometrial cancer cell proliferationimplications for a novel treatment strategy. Gynecologic Oncology 2010; 116 (1): 92-98.

37. Kumar S, Meuter A, Thapa P, Langstraat C, Giri S, Chien J et al. Metforminin- take is associated with better survival in ovarian cancer:A case-controlstudy. Cancer 2013; 119: 555-562.

38. Lee DJ, Kim B, Lee JH, Park SJ, Hong SP, Cheon JH. et al. The effect of metformin on responses to chemotherapy and survival instage iv colorectal cancer with diabetes. Korean J Gastroenter 2013; 60: 355-361

39. Memmott RM, Mercado JR, Maier CR, Kawabata S, Fox SD, Dennis PA Metformin prevents tobacco carcinogen-induced lung tumorigenesis. Cancer Prev Res 2010; 3: 1066-1076.

40. Sadeghi N, Abbruzzese JL, Yeung SC, Hassan M, Li D. Metformin use is associated with better survival of diabetic patients with pancreatic cancer. Clin Cancer Res

Metforminin Melanom Cilt Kanserine Etkisi - Alp ve ark. 
2012; 18: 2905-2912.

41. Fang Z, Xu X, Zhou Z, Xu Z, Liu Z. Effect of metformin on apoptosis, cell cycle arrest migration and invasion of A498 cells. Molecular Medicine Reports 2014; 9 (6): 2251-2256.

42. Patel S, Singh N, Kumar L. Evaluation of effects of metformin in primary ovarian cancer cells. Asian Pac J Cancer Prev 2015; 16 (16): 6973-6979.

43. Queiroz EA, Puukila S, Eichler R, Sampaio SC, Forsyth HL, Lees SJ. et al. Metformin induces apoptosis and cell cycle arrest mediated by oxidative stress, AMPK and FOXO3a in MCF-7 breast cancer cells. PloS one 2014; 9 (5): e98207.

44. Kang MH, Reynolds CP. Bcl-2 inhibitors: targeting mitochondrial apoptotic pathways in cancer therapy. Clinical Cancer Research 2009; 15 (4): 1126-1132.

45. Adams JM, Cory S. The Bcl-2 protein family: arbiters of cell survival. Science 1998; 281 (5381): 1322-1326.

46. Tomic T, Botton T, Cerezo M, Robert G, Luciano F, Puissant A. et al. Metformin inhibits melanoma development through autophagy and apoptosis mechanisms. Cell Death \& Disease 2011; 2 (9): e199.

47. Do K, Doroshow JH, Kummar S. Weel kinase as a target for cancer therapy. Cell Cycle 2013; 12 (19): 3348-3353

48. Lorenzo HK, Susin SA, Penninger J, Kroemer G. Apoptosis inducing factor (AIF): a phylogenetically old, caspase-independent effector of cell death. Cell Death and Differentiation 1999; 6 (6): 516

49. Liu H, Scholz C, Zang C, Schefe JH, Habbel P, Regierer AC. et al. Metformin and the mTOR inhibitor everolimus (RAD001) sensitize breast cancer cells to the cytotoxic effect of chemotherapeutic drugs in vitro. Anticancer Research 2015; 32 (5): 1627-1637.

50. Tsai CC, Chuang TW, Chen LJ, Niu HS, Chung KM, Cheng JT. et al. Increase in apoptosis by combination of metformin with silibinin in human colorectal cancer cells. World Journal of Gastroenterology 2015; 21 (14): 4169.

51. Ma L, Wei J, Wan J, Wang W, Wang L, Yuan Y. et al. Low glucose and metformininduced apoptosis of human ovarian cancer cells is connected to ASK1 via mitochondrial and endoplasmic reticulum stress-associated pathways. Journal of Experimental \& Clinical Cancer Research 2019; 38 (1): 77.

52. Wu N, Gu C, Gu H, Hu H, Han Y, Li Q. Metformin induces apoptosis of lung cancer cells through activating JNK/p38 MAPK pathway and GADD153. Neoplasma 2011; 58 (6): 482-490. 